\title{
On Transforming Unused Urban Spaces to Social Housing for Self-Employed People in Ho Chi Minh City: An Architectural Space Design Proposal
}

\author{
Le-Minh Ngo ${ }^{1, * \mathbb{C}}$, Hai-Binh Nguyen ${ }^{1}$, Thi-Phuong Uyen Nguyen ${ }^{2} \mathbb{C}$ and Thi-Minh Dieu Nguyen ${ }^{3}$ \\ 1 Faculty of Civil Engineering, Ton Duc Thang University, Ho Chi Minh City 700000, Vietnam; \\ nguyenhaibinh@tdtu.edu.vn \\ 2 Research Center of Environment, Southern Institute of Social Sciences, Ho Chi Minh City 700000, Vietnam; \\ tqmleader@gmail.com \\ 3 Faculty of Engineering and Technology, Hong Bang International University, \\ Ho Chi Minh City 700000, Vietnam; minhdieu36@gmail.com \\ * Correspondence: ngoleminh@tdtu.edu.vn
}

Citation: Ngo, L.-M.; Nguyen, H.-B.; Nguyen, T.-P.U.; Nguyen, T.-M.D. On Transforming Unused Urban Spaces to Social Housing for Self-Employed People in Ho Chi Minh City: An Architectural Space Design Proposal. Sustainability 2021, 13, 12175. https: //doi.org/10.3390/su132112175

Academic Editor: Nicholas Chileshe

Received: 4 September 2021

Accepted: 26 October 2021

Published: 4 November 2021

Publisher's Note: MDPI stays neutral with regard to jurisdictional claims in published maps and institutional affiliations.

Copyright: (c) 2021 by the authors. Licensee MDPI, Basel, Switzerland. This article is an open access article distributed under the terms and conditions of the Creative Commons Attribution (CC BY) license (https:/ / creativecommons.org/licenses/by/ $4.0 /)$.

\begin{abstract}
As with many metropolitan areas, social housing $(\mathrm{SH})$ provision, which can improve living standards and social welfare, is crucial for urban socio-economic development strategies in Ho Chi Minh City (HCMC). However, there have been issues relating to promoting social housing in the Vietnamese context resulting from the property market and the design. The former is a failure to attract investors. The latter relates to lacking housing models for the mid- and low-income communities. Currently, many low-income families who have low access to the general job market in HCMC have to make a living by running their own business at home. This situation leads to low-income housing establishments in some residential areas. Thus, the planning approach in social housing needs to solve both the demand for low-cost housing and promoting self-employed activities. In this paper, mixed methods, including observation, questionnaires, interviews, data aggregation, and comparison, were conducted with supporting legal conditions and corresponding operating conditions to propose appropriate designs for the SH for self-employed people in HCMC. First, observing and analyzing urban spaces helped identify the unused urban areas that solve the investment issue. Then, after studying the development of social housing in different contexts via the questionnaire and in-depth interviews, self-employed households' basic information and their business needs in using SH spaces were identified in some districts. Then, based on the legal framework and practical projects, optimal space designs were formed.
\end{abstract}

Keywords: social housing; self-employed people; unused urban space; Ho Chi Minh City

\section{Introduction}

The open-door policy and multisectoral economic development directly drive all urban activities. In Ho Chi Minh City (HCMC), social housing (SH) is considered a solution to improve living conditions to stabilize social, economic, and environmental urban development [1]. In HCMC, most self-employed people who are low income live in the outskirts of the city, such as Thu Duc city, District 9, and District 12. Their settlement is mainly temporary houses made of low-quality recycled materials, including coconut leaves; raincoats; oil papers; cartons; pallets; old, corrugated iron; or industrial wastes. The architectural form is poor, the colors are somberly created from wasted and recycled materials. The living spaces are composed with minimal functions (See Figures 1 and 2) [2]. The infrastructure for residential areas is lacking. The quality of the living environment is poor because of carelessness from the government. The appearance of many dangerous diseases is imminent in these areas. There are still many people who have to make a living from unstable jobs, although they already had a home, especially self-employed ones who 
do not belong to any formal organization and have low income [3]). According to the VeT organization (a non-governmental organization operating in Vietnam, specializing in urban and housing improvement for low-income people), low-income is classified in the range between 25 USD and 265 USD per month, which is lower than the average income rate of HCMC. According to the World Bank (WB), a self-employed person having a low income has to spend at least $66 \%$ of their earnings on food and drink. The remaining $34 \%$ is spent on other fundamentals, such as housing, health care, and education. The monthly income of these people is just enough to cover essential daily expenditure [4]. Because of that, their living standard is just slightly above the minimum level. Therefore, the development of social housing in Ho Chi Minh City is urgent to maintain the fabric of society and improve the quality of life through (1) meeting the affordable housing demands for low-income people and (2) promoting economic values [5].

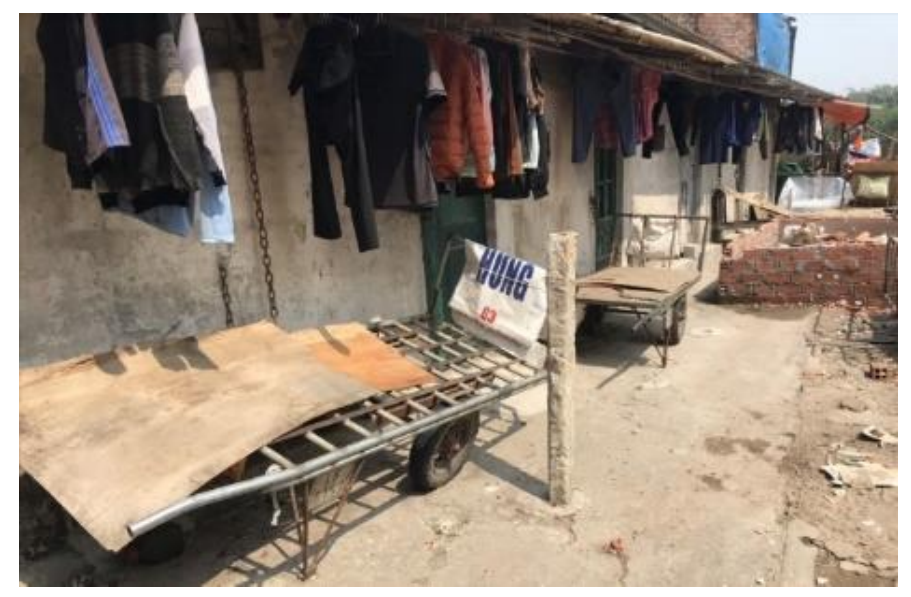

Figure 1. Current status of living space of migrant workers in HCMC, with front porch for transporting equipment and space for drying clothes (Source: [6]).

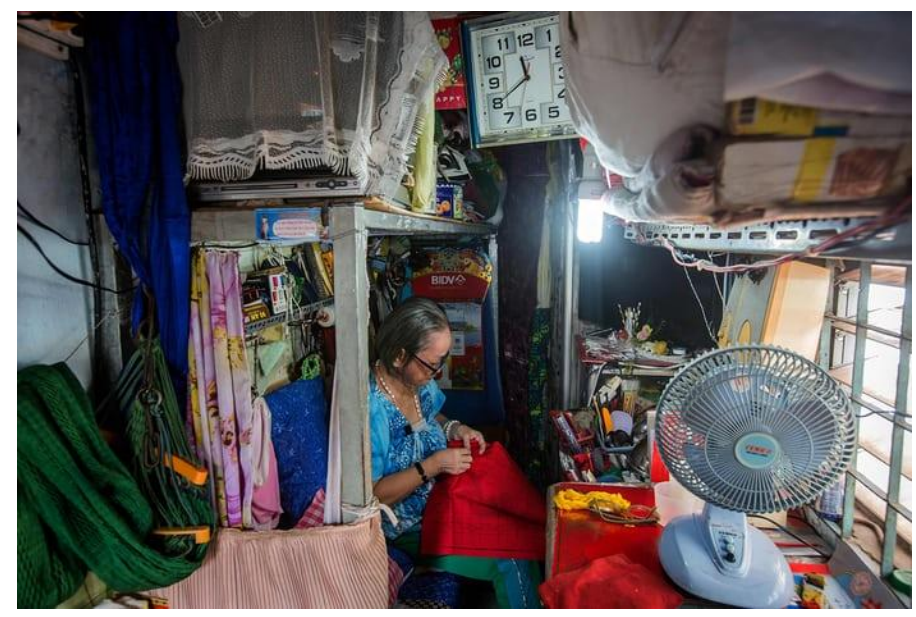

Figure 2. The cramped living space combines with the living and manual work of employers (Source: [7]).

The implementation process shows that there are still many inadequacies and difficulties in the development of social housing, which focuses on the issue of space design and development. The investment in developing social housing has not yet attracted investors to participate in the social housing market because the policies on some administrative procedures are still complicated, such as having to appraise the selling price, rental price, controlling profits, limited land funds, etc., causing difficulties for investors [8].

In Vietnam, the social house provides for people specified in the policies on housing support in the Housing Law 2014 [1]. In Articles 53 and 58 of this Law, there are forms 
and preferential policies of social housing development. The government invests in social housing with various sources of budget. The capital would be the state budget, national bonds, development subsidies, concessional loans from donors, and national investment credit. The other sources can come from the build-transfer contract in the construction project, in which land is determined to build social housing under regulations for lease or purchase. However, to reduce the budget for SH development, the government encourages socialization policies. The socialization policy enables the private sector to develop social housing, including enterprises, cooperatives, households, and individuals. The policy supports investors to lease or sell with the state's incentives, such as exemption from land use tax. The land for SH development is the state's land and could be provided for investors. The government also reduces or exempts investors from value-added tax (VAT), income tax to attract investors. Preferential loans from the bank or being funded by the People's Committee in the infrastructure construction of $\mathrm{SH}$ are also new regulations to ensure SH develops effectively [1]. In addition, according to current Vietnamese standards on social housing, the apartments are large and sold at a high price. Therefore, poor people cannot afford this type of housing, so they sell their priority of buying SH to others. This situation creates a speculative price issue.

In the previous project, because of lacking research on living spaces designed for lowand mid-income groups, the $\mathrm{SH}$ products cannot meet the demand for housing for those people. In choosing the location for construction, the $\mathrm{SH}$ projects are often arranged in suburban areas or newly expanded districts. Besides selected spaces, unused spaces in the city or spaces in the "pending plan" (the state of a land area that has been recorded by a competent state agency in the land use plan for one or more different purposes, announced to be retrieved for the implementation of the plan, but the owner still does not carry out the planned schedule) should be considered for the SH projects [9,10]. These types of spaces can be used to provide the urgent need for social housing through land use transformation supervised by the government. Accordingly, significant benefits will be achieved, such as reusing or revitalizing abandoned spaces, promoting public transport accessibility, enabling more people to access the job market.

The form of social housing for self-employed workers was developed in Southeast Asian countries in the late 20th century. In some areas, slums with ineffective land use planning have been carried out by some studies. Based on that, the government takes advantage of the reclamation and reuse of these spaces to develop social housing to improve and ensure the living conditions for people, especially freelancers. Typically, in Thailand, according to research by the group of authors Nattawut Usavagovitwong, Aim-on Pruksuriya, Wanida Supaporn, Chaiwat Rak-U, Diane Archer, and Gordon McGranahan [11], low-income groups prefer to live in "under-living standard" areas such as slums instead of affordable low-income housing areas because of money making advantages. At the same time, the research checks the identification of low-rise, low-income housing of communities in slums or "Baan Mankong" areas (housing built by the community through the government's support where the community is organized with elected representatives managing the households; monthly repayment of the 15-year collective loan provided by CODI for the upgrade.). Besides, the ineffective land use compared to communal apartments in Bangkok, Thailand, is also uncovered. In Indonesia, in the city of Surakarta, "Kampung" settlements (a settlement or concentrated community, population density from low to high, where low-income families usually live. Kampung was developed as a result of urbanization, where urbanites from the same rural area lived close together and originally settled in the suburban areas.) are developed in association with food supplement and employment, similar to the community houses in Bangkok. The sustainable development of the "Kampung" in Surakarta is based on the resident's perception and ideas in all the planning and infrastructure construction [12].

In the residential areas of Baan Mankong, Bangkok, when organizing home space for "freelance workers" (the majority of residents living here work in the unofficial economy as street vendors, taxi drivers, and other self-employed activities), there is an open space at 
the front of the house to store the equipment and mobile kiosks of street vendors. These open spaces are used for socializing, cooking, and commercial activities. The majority of the ground floor is for goods shelves and other equipment storage. The ground floor is optimized for business activities, while the living spaces are organized on the upper floor. This form of organization is well known as "street house" in the Vietnam context. In recent years, some social housing projects have considered engaging the business above spaces in the implication model. Due to such interactions, social housing transformation needs to be viewed synthetically, with all aspects of sustainability in general $[13,14]$.

From the current situation of social housing development, particularly in Ho Chi Minh City, it is urgent to find the solution for low-cost housing that enables poor people to run their businesses for living at home. Through the survey and analysis of urban space, the research team proposes unused urban spaces that can be utilized for the $\mathrm{SH}$ construction. Taking advantage of these spaces helps to optimize the use of urban spaces and reduce pressure on land demands, reducing investment costs as well as pressure from land compensation and clearance and infrastructure investment. Based on people's needs and basic housing design requirements, the research team will propose the design of a house for low-income people in Ho Chi Minh City with the following criteria: (1) private spaces but can be opened when needed; (2) multi-function (diverse activities) in the same space at many times; and (3) can develop a business at home. From there, a model of social housing is proposed, with four solutions to organize space for self-business activities according to different levels of space conversion, including fixed space, self-business, reloading space, and multi-faceted space.

\section{Materials and Methods}

This study aims to analyze the demand for social housing with relative requirements in the current status of specific areas in Ho Chi Minh city. The mixed methods, including observation, questionnaires, interviews, data aggregation, and comparisons, are conducted to approach the research objectives. The provision of social housing is for people who have low access to the housing market. Therefore, SH development helps maintain the city's diverse fabric of society by (1) ensuring the affordable housing provision is targeted at low- and middle-income households and (2) forcing economic values [15]. To develop affordable housing in HCMC, eight requirements are grouped into three main basic criteria: quality, accessibility, and design (Table 1).

Table 1. Criteria to develop SH in HCMC.

\begin{tabular}{|c|c|c|}
\hline No. & Criteria & Requirements \\
\hline 1 & Quality & $\begin{array}{l}\text { 1. Structure and 2. Construction: ability for conversion/extension, } \\
\text { installation quality of building sections (ceiling, doors, windows), age } \\
\text { 3. Building services and } 4 \text {. Health safety and security, promoting natural } \\
\text { factors: natural lighting, ventilation, water supplement, and sanitation } \\
\text { 5. Users comfort: thermal comfort, ventilation } \\
\text { 6. Maintenance: easy to maintain }\end{array}$ \\
\hline 2 & Accessibility & 7. Site Planning: location and layout, access to city transport, job market \\
\hline 3 & Design & $\begin{array}{l}\text { 8. Architecture: distinctive characteristics, appearance of house/apartment, } \\
\text { space organization serving basic needs (rooms, kitchen, bath, lounge) }\end{array}$ \\
\hline
\end{tabular}

The investigated areas are located in Go Vap and Binh Thanh District. The reasons for choosing these areas are the specific location and demographic characteristics. Go Vap and Binh Thanh District are along the two main national road routes, QL1A and QL13. These two districts are planned as the entrance of HCMC from the northern cities and Highland cities. Moreover, these two districts take advantage of connecting with the city center (See Figure 3). Due to these characteristics, Go Vap and Binh Thanh districts have diverse demographics and labor markets. 


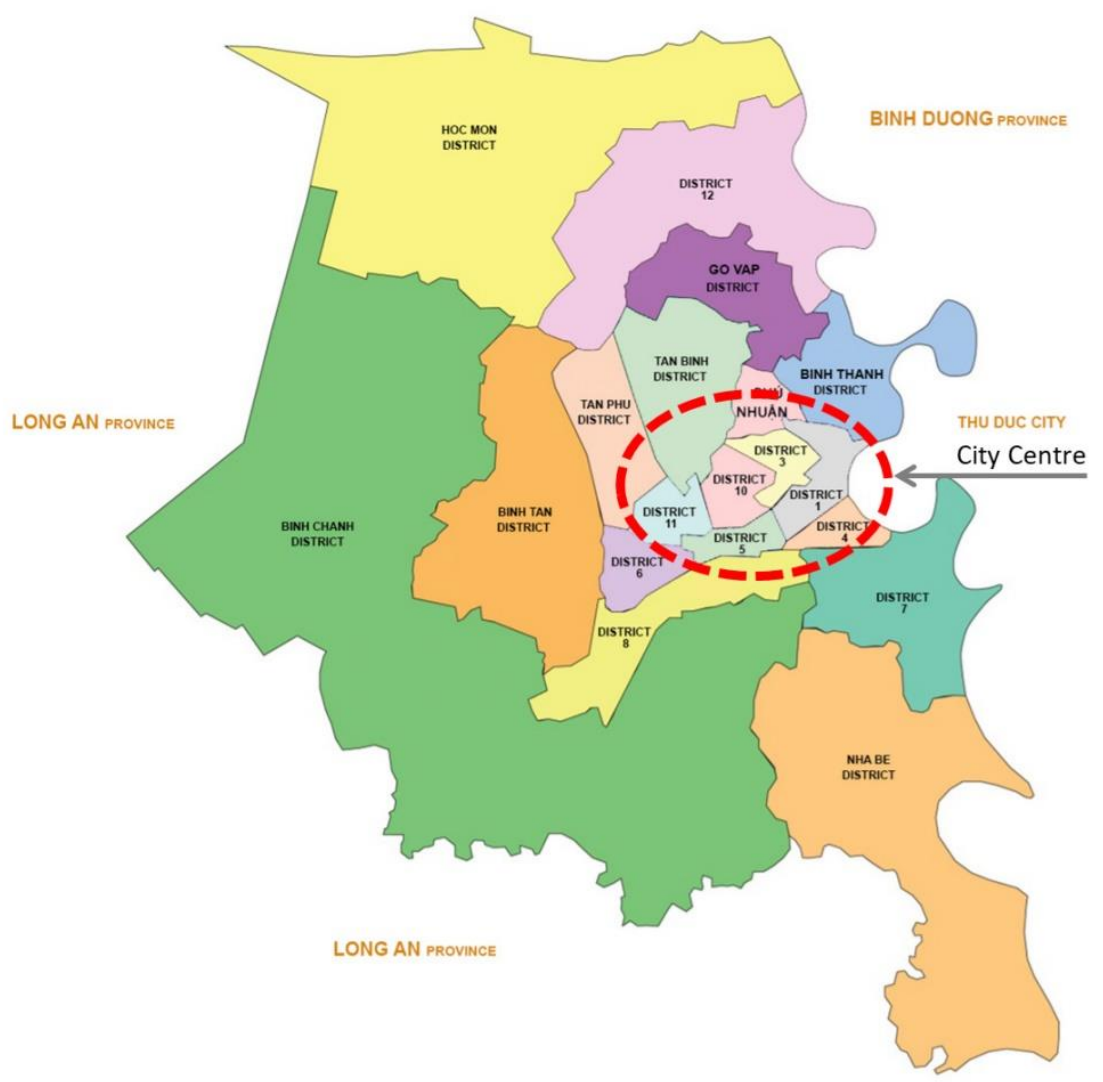

Figure 3. Location of Go Vap and Binh Thanh District on the map of Ho Chi Minh City (Source: This figure is created by the authors).

Based on some key stakeholders' views, SH development tendencies will be explored. Through observation, the general situation of the investigated site is clarified, including the network of potential spaces to develop SH, essential needs, and lifestyles of selfemployment. A list of photos is recorded after each survey to ensure data accuracy from questionnaires and interviews. The questionnaires are conducted in 30 households who are self-employed in each ward of the two mentioned districts with four sections. The samples are in low- and mid-income groups. The first section is to collect the local living conditions of the study area and the general perceptions of people about SH. In the following section, the daily lifestyle, experiences, and psychological characteristics of the users are identified. Questions regarding the need to use spaces to live and to conduct trading activities are listed in the third section. Finally, levels of flexibility in living space organization are evaluated by the participants. Representatives, including the managers of wards, headers of each building block, and security guard, are chosen as core samples for an interview with the same structure of questionnaire information. In total, 210 samples are carried out. The study concentrates on analyzing the collected data in Sections 3 and 4. The data from the first two sections are used to compare and check with Sections 3 and 4 to ensure the solution of SH meets the demand of local communities.

Data evaluation and analysis are implemented by descriptive statistical methods by IBM SPSS software. Multiple percentage calculations are mainly used to process data from the questionnaires to distribute various indicators in groups and identify accumulative percentages.

\section{Current Situation of Social Housing Development}

The term "social housing" was developed in the UK, USA, and Canada in the 1970s and gradually spread to Asian countries, such as Japan, Korea, and China. SH is provided to poor people who have no income or insignificant income [8,10]. In Vietnam, SH is also developed for social balance goals without any business purposes. The $\mathrm{SH}$ is accommo- 
dation for those who cannot afford a house or an apartment with the primary function. According to Articles 49, 50, and 51 of the Housing Law in 2014, SH is invested in by the government. SH is provided for people who can prove that they are in a low-, mid-, or no income group and (1) they do not own residential land or housing or (2) the house is an insufficient living space for all family members or (3) the house is damaged. In Vietnam, the concept of social housing has a narrower scope than affordable housing because of the policies for implementation and users [1]. In most cases, the $\mathrm{SH}$ is mainly located in remote and unattractive locations or planned for poor living quality. Hence, the social housing policy is controversial. Some people argue that $\mathrm{SH}$ provides affordable housing for many different households while SH brings living conditions [16]. In most SH projects, the poor social network and facilities requirements have been highlighted. However, in the future development strategies of $\mathrm{HCMC}$, the $\mathrm{SH}$ would provide a large number of living spaces for vulnerable groups (see Figure 4).

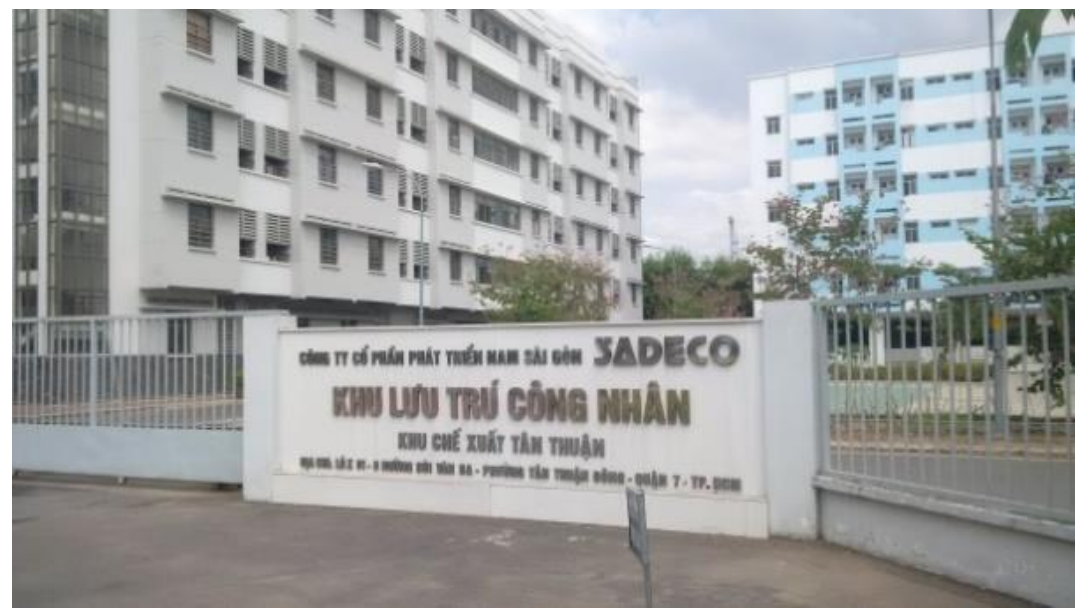

Figure 4. House for workers in District 7, HCMC (Source: This photo was taken by the first author).

Moreover, the social housing projects are sold at a high price which exceeds the ability of low- and mid-income people. This situation results from speculation and fluctuation of the housing market. Therefore, to have a lower price, social housing has a lower quality of construction. In recent years, SH development in HCMC has had four main issues: (1) identification of land use with priority for social housing development by the government, (2) accessibility to the labor market from the SH location, (3) capital for $\mathrm{SH}$ development, and (4) the gap between design criteria and users. These issues are detailed in Table 2 below.

Table 2. The issues of SH development in HCMC.

\begin{tabular}{cl}
\hline Criteria. & \multicolumn{1}{c}{ Issues } \\
\hline Quality & $\begin{array}{l}\text { The social housing with low quality of construction: degradation after a } \\
\text { short term of use. } \\
\text { Social houses criteria of government policies are sufficient facility, spaces } \\
\text { with good quality: the price is very high so that low- and mid-income } \\
\text { households cannot afford it and they sell their plots to others. }\end{array}$ \\
\hline Accessibility & $\begin{array}{l}\text { A new residential area is often located far from the center or the main urban } \\
\text { routes, which causes significant disadvantages for people who mainly make } \\
\text { a living by trading activities. }\end{array}$ \\
\hline Design & $\begin{array}{l}\text { The living space has not been designed to meet the lifestyle and daily needs } \\
\text { of low- and mid-income people. }\end{array}$ \\
\hline
\end{tabular}

In conclusion, $\mathrm{SH}$ development in HCMC has four main issues, including (1) identification of land use with priority for social housing development by the government, (2) 
accessibility to the labor market from the SH location, (3) capital for the SH development, and (4) a gap between design criteria and users.

Lifestyle and psychological characteristics of self-employed people are clarified by questionnaire and interview in seven wards of the Binh Thanh and Go Vap Districts. The results show that their trading activities do not need huge capital, specific instruments, or skills. Therefore, many people who are not well educated or professionally trained run small businesses. The majority of participants know that they are in the lowest income group. Their income is unstable. They have to accept this situation and try to earn money that is just sufficient to pay for basic daily needs. Self-employed people in the survey are mainly women. They have to walk from the early morning to sell goods. Their business depends on social networks, economic relationships, seasonal job opportunities, and various sources of subsidy (see Figures 5 and 6). A group of people who suffer the same situation connect and make a community in some residential areas. These communities share the economic interest as well as social benefits and create a specific urban social pattern [17].

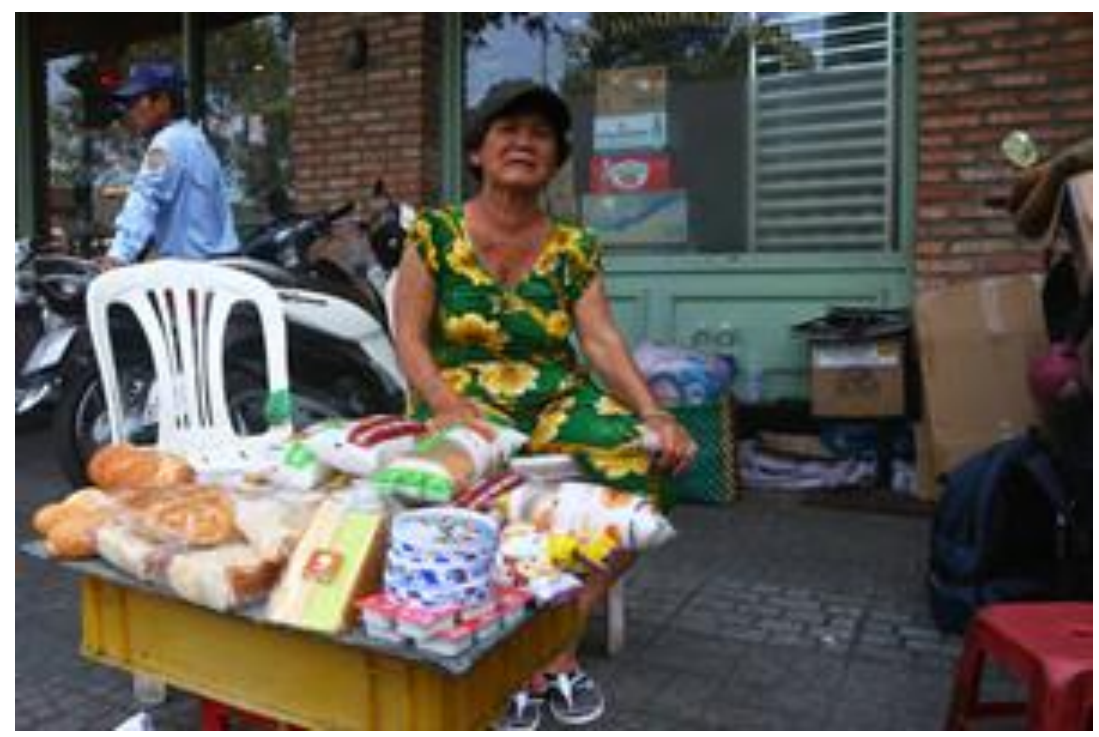

Figure 5. Self-employed people in HCMC (Source: This photo was taken by the first author).

The mentioned self-employed people cannot join the urban job market and their selfemployment is considered the informal economic sector [18]. The reason is that these types of trading activities are freely developed and not managed by any official organization. Therefore, currently, there is no program or policy on finance or planning and management for social housing for self-employed people. 


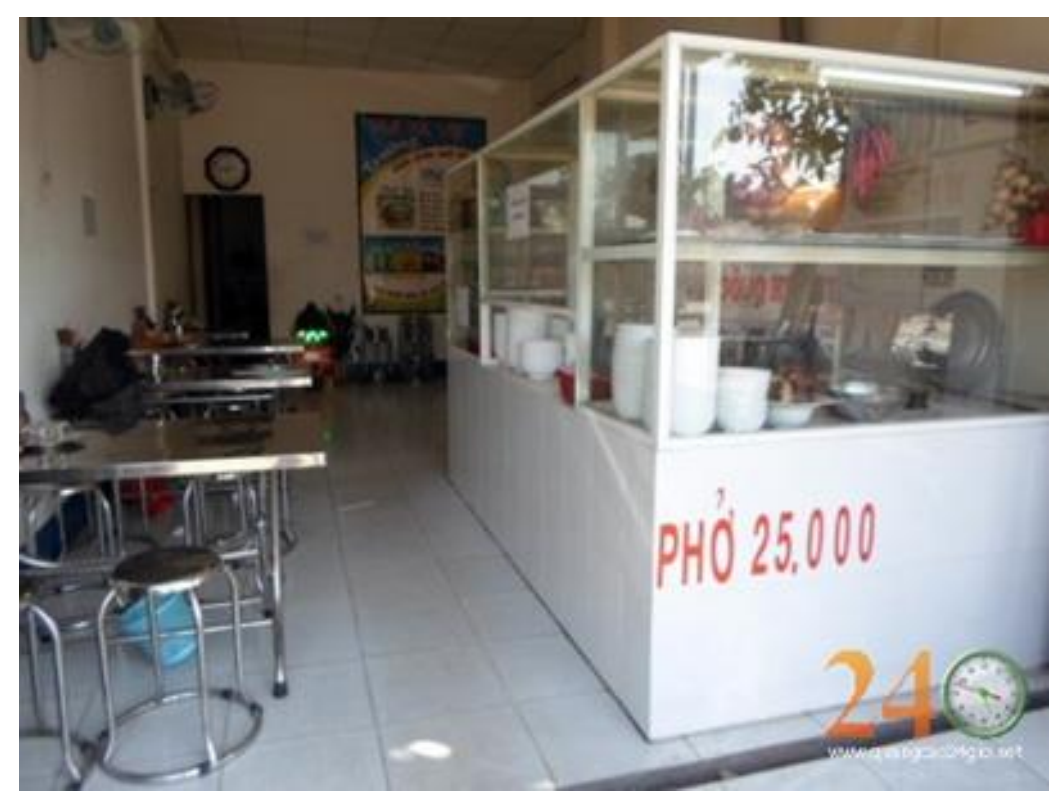

Figure 6. Pho stall with an area of $2 \mathrm{~m} \times 3 \mathrm{~m}$ space on the ground floor of a self-business (Source: [19]).

\section{Possibility to Make Use of Unused Spaces in Urban Areas}

"Unused space" is considered a part of urban public space. The space lies outside or between the buildings, under the flyover, or the empty space in the park. Unused spaces are also determined by the market or limited by the facade of the buildings, the ground, the sky, or green spaces. Currently, these spaces have not been used effectively by the community. Many of them are vacant land or even abandoned for a long time with poor conditions and expected suitable solutions [18]. Regarding the housing development under the flyover in Hong Kong, where the land value and population density are too high, there have been proposals to build houses under the bridge. However, these proposals have not been implemented yet. To ensure the feasibility of solutions, it is necessary to have more in-depth studies with sufficient scientific and practical analysis in each context [20,21]. In this paper, the research proposes transforming the unused space in the study area as a reference model for future research. Unused spaces in urban areas are defined with the following basic characteristics and benefits:

- Unused space is a place to organize social activities and exchanges, encourage people to communicate with each other, rest, entertain, undertake sports.

- Unused space can adjust the living environment in terms of climate (balance of temperature, humidity, natural ventilation), limit dust in the air, reduce noise in living areas, and improve sanitation and environmental quality.

- Unused space provides cultural and aesthetic needs. The space organization and decoration will positively affect people's psychology and adjust their behavior to the environment.

In fact, unused space in Ho Chi Minh City is often exploited and used for many different informal purposes. However, their use function has changed, partially or entirely. They are no longer serving the community and creating urban beauty. For example, space at the foot of overpasses, the empty spaces in public parks, or the spaces running along rivers or canals are gradually being polluted due to being occupied with serving spontaneous business activities, street vendors, and parking lots, instead of providing space for the community. Currently, in Ho Chi Minh City, we can find possible unused spaces to intervene, including (1) parks-vacant land plots or rarely used by the community, (2) the space above the parking lot, the training ground, (3) at the foot of the overpass (the space below the foot of the bridge is vacant or only used as the parking lot and to plant trees) (see Figures 7 and 8), (4) people's markets, and (5) degraded dormitory areas which are waiting to be cleared. Suppose the mentioned spaces are transformed into social 
housing or temporary housing. In that case, it needs to ensure a technical infrastructure system connection, sanitary requirements, environment, and housing architecture without affecting adjacent structures.

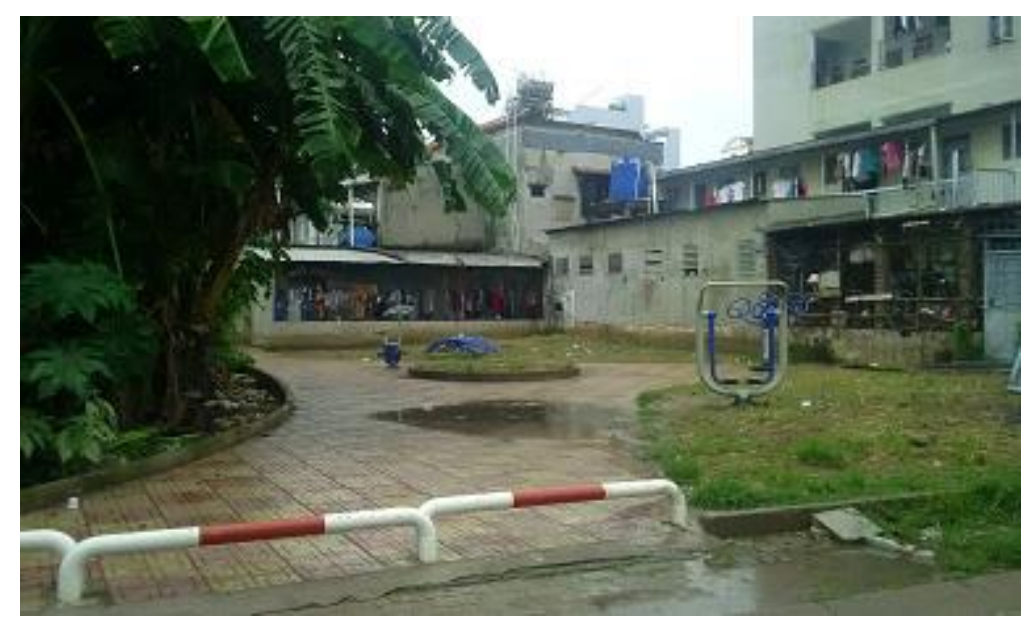

Figure 7. The potential unused spaces in urban areas (Source: This photo was taken by the first author).

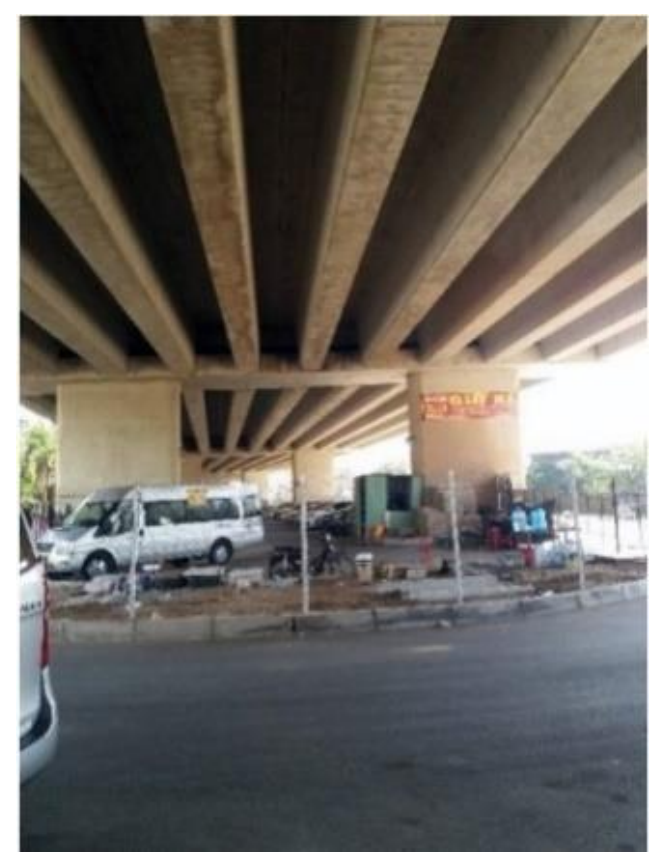

Figure 8. Unused space is occupied under the overpass in HCMC (Source: This photo was taken by the first author).

In conclusion, with the idea of using unused space in urban areas to develop social housing, the poor bring huge economic and social benefits. If the idea is implemented, it will help to serve a huge demand for housing in HCMC. Solutions to utilize the empty space in urban areas as housing for the poor people will improve social security and the quality of life, and enhance the cultural and spiritual life of the communities, particularly workers (see Figures 9 and 10). 


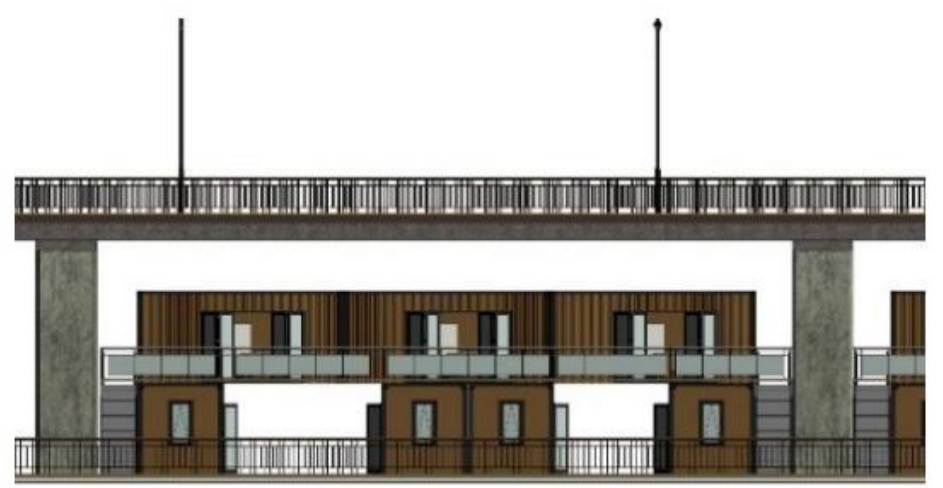

Figure 9. The idea of designing a housing area for the poor people at the foot of Phu My Bridge, District 7, HCMC (Source: This figure is created by the authors).

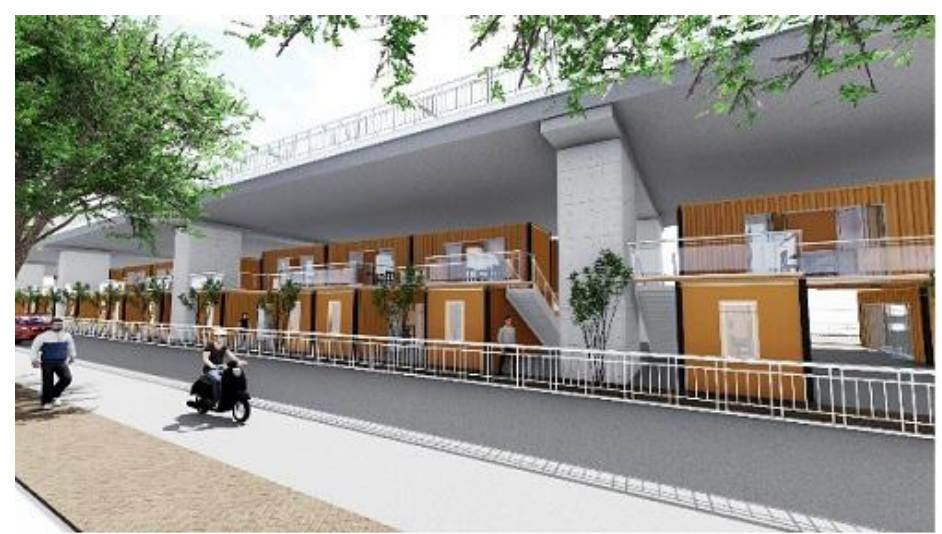

Figure 10. The idea of designing a housing area for the poor people at the foot of Phu My Bridge, District 7, HCMC (Source: This figure is created by the authors).

\section{Proposed Solutions for Organizing Space for Social Housing}

The data are collected from the survey conducted with 210 questionnaires in seven wards of Binh Thanh District and Go Vap District, Ho Chi Minh City, in 2019. According to the second section of the questionnaire, the lifestyle characteristics of self-employed people are identified. The third group of questions is related to the needs of self-employed people to use spaces in their houses. Accordingly, even though the space is still limited, employees always want to ensure their privacy and, at the same time, that the private space is able to open with surrounding spaces if needed. This is explained by their tendency to have neighboring relationships remain (neighbors, colleagues, and even acquaintances share the same house). The openness of the self-employed people's housing spaces also promotes job opportunities, sources of profit, and makes it easier to receive support in an emergency. Respondents' feedback also shows that workers need flexible spaces, which flexibly transform from private mode to trading mode during the daytime.

Based on the collected data in the fourth section, the solutions for the flexible spatial organization are capable of serving many living and trading activities. Self-employment activities repeat daily at a specific timeframe. Therefore, the ground floor planning should avoid closed spaces or private functions. Instead, flexible and multi-purpose spaces are added. In each type of spatial organization, the flexible level in space transformation and using values of the house is identified based on the flow of activities of self-employed people [22,23], the timeframe, and specific jobs of each family member. The authors propose centralized functions with the relative properties changed flexibly by various timeframes. A single space can be coordinated with diverse functions, such as trading, welcoming guests, family gathering activities, studying, working, worshipping, reading and sleeping, eating and cooking, and preparing goods for sale [24]. 
Based on the survey results, the authors propose several solutions to organize housing space for self-employed activities in Ho Chi Minh City. There are four main types of spaces below, including fixed space, self-business, reloading space, and multi-faceted space.

- $\quad$ Fixed space (see Figure 11)
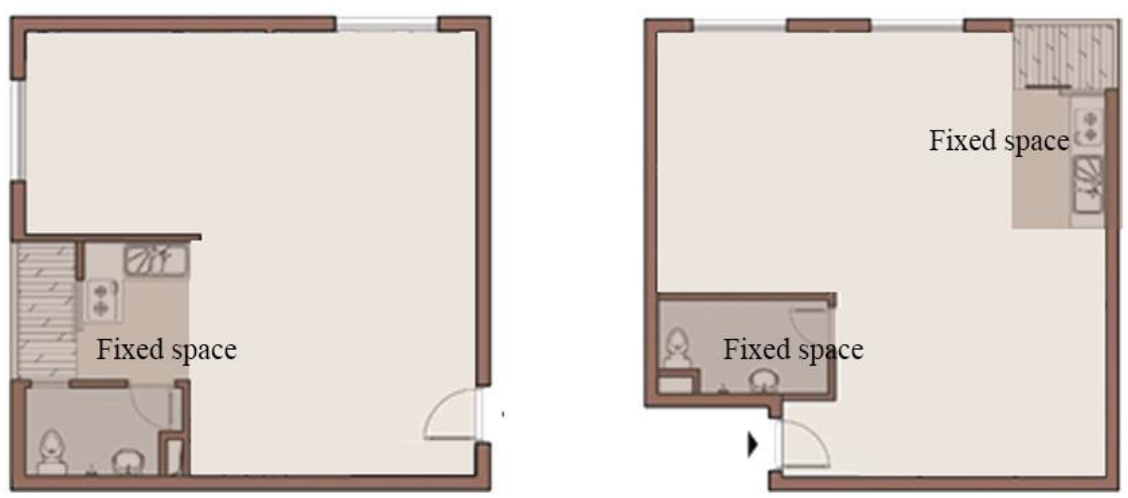

Figure 11. Fixed space for self-employed people.

The space that serves the main function is fixed and almost unchanged over time. This space is for the basic needs of family members, often combined with the hard infrastructure of buildings. There are two types of fixed space: (1) closed fixed space (toilet) and (2) opened fixed space (kitchen, courtyard, etc.).

- $\quad$ Self-business space (see Figure 12)
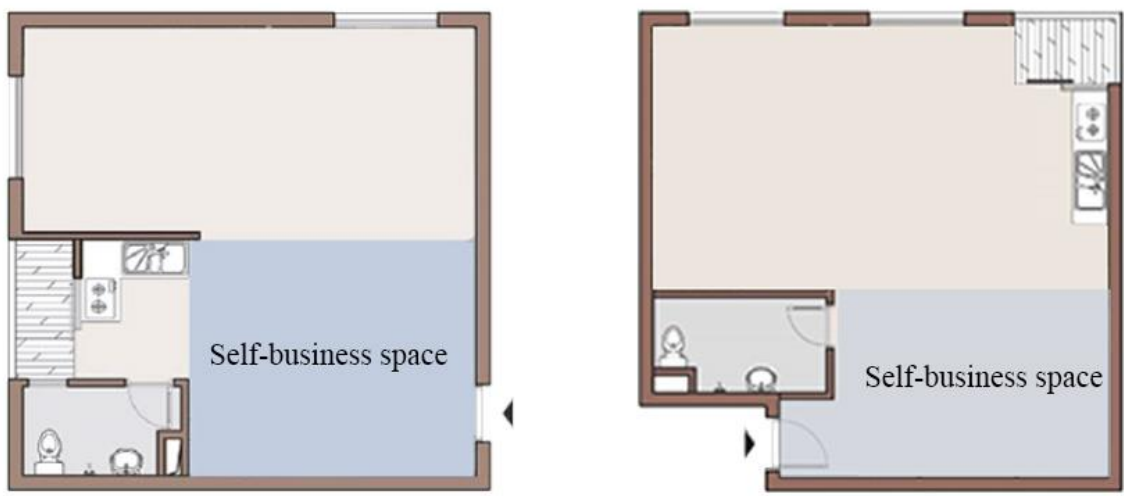

Figure 12. Self-business space for self-employed people.

To meet business needs and carry out economic activities, the authors propose to organize a self-business space in apartments or on the ground floor of a house. It is the first exposed space when entering an apartment. This space is a place to communicate, exchange, buy and sell goods, or other self-employed activities (see Figures 6 and 11).

For the social space for self-employed people, the "self-business" space is the soul of an apartment. Depending on the characteristics of family members, it will be a place for work, selling, tools storage, or connect to a fixed space. This can be used as the kitchen. It can be seen that the space is mainly used for business activities. After hours of working, it will become a family gathering activity. Besides being a business space, it is a place for social communication by enabling neighbors to come and sit. By promoting neighborhood engagement, this type of space helps to increase empathy and strengthen social relationships. In many cases, running this type of space can increase opportunities for self-improvement through social networks. This process helps to improve the quality of life and form a motivation for the local community in social housing.

- $\quad$ Reloading space (see Figure 13) 

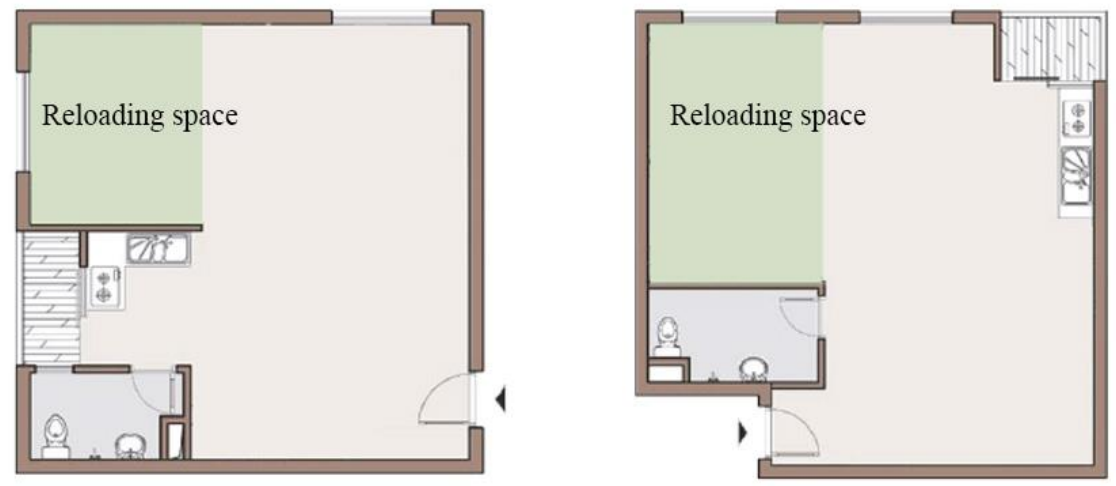

Figure 13. Reloading space for self-employed people.

As mentioned above, employees need to ensure individuality in their own space but, at the same time, they still need a certain openness with the surrounding spaces. They tend to have stable neighboring relationships (neighbors, colleagues) which can be a source of information for job opportunities. Therefore, the proposed reloading space is an open but private space at the same time, based on the 3-wall technique, where adjacent spaces are created. This solution aims to ensure individuality and the openness for the reloading space and the adjacent spaces. Thereby the spatial use is maximized

- $\quad$ Multi-faceted space (see Figure 14)
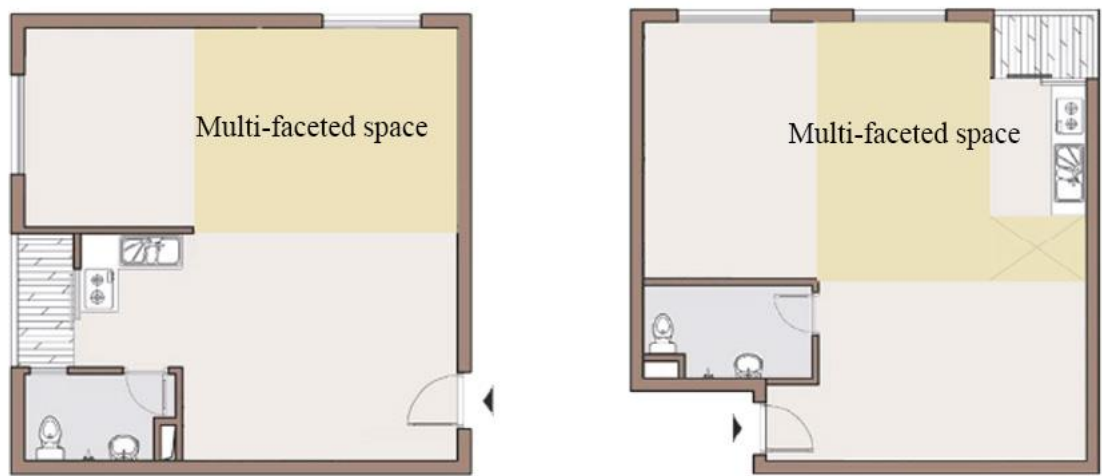

Figure 14. Multi-faceted space for self-employed people.

Multi-faceted space plays a role as a buffer space. It is neutral with flexible functions, from private use to shared use. This type of space has the potential to convert into a self-employed space (Figure 12) or a reloading space (Figure 13), and vice versa. Reloading space and self-employed space may be expanded, encroached on by the multi-faceted space, and vice versa, with a specific partition that may make use of space in different floors and areas (See Figure 15).
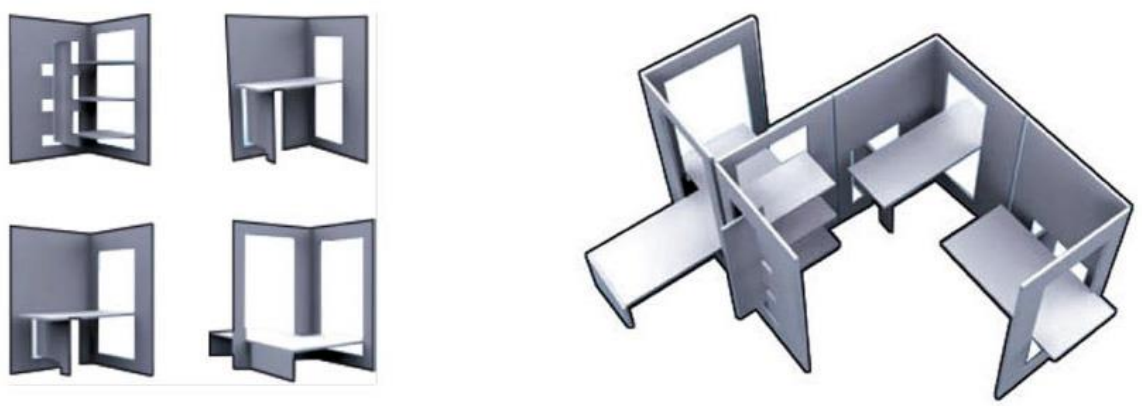

Figure 15. Proposed solution for division in multi-faceted space for self-employed people. 
Thus, to effectively exploit spaces for living and trading at many times of the day, the authors aim to organize a flexible space that is capable of serving many activities. The solution is to create a flexible space inside many other spaces for users demands without breaking the main structure of the house. This space can include semi-private activities of family members such as studying and working (see Figure 16). These figures as below are created by the authors. Table 3 summarizes the characteristics of the proposed types of multi-faceted space.
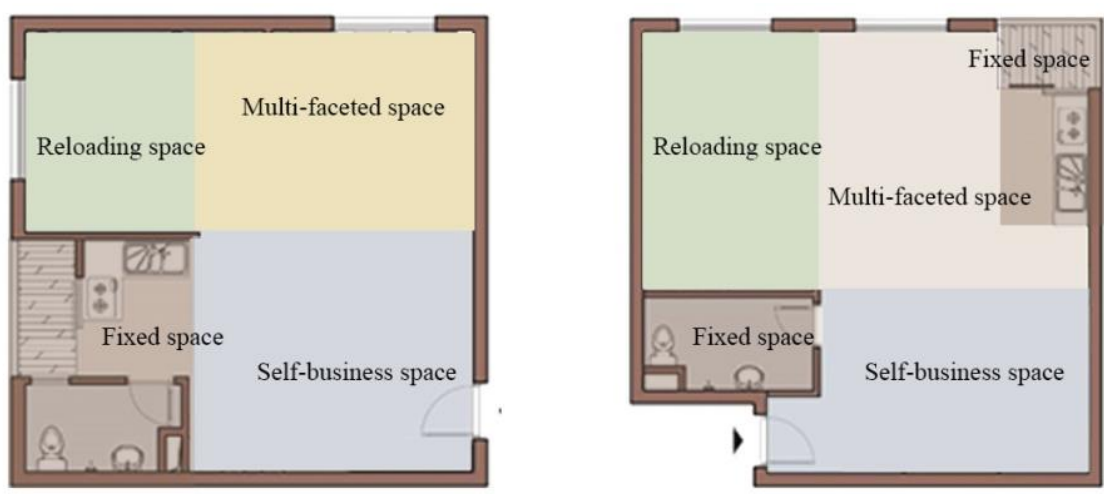

Figure 16. Organization of housing ground with four types of flexible spaces.

Table 3. Summary of all characteristics of four types of space design.

\begin{tabular}{ccccccc}
\hline Spaces & Volume & Limit & Function & Characteristics & Connection & Position \\
\hline Fixed space & Small & $2+2$ facet & Shared & Unchangeable & Other spaces & One side \\
\hline Self-business space & Large & Door & $\begin{array}{c}\text { Communicate } \\
\text { with others }\end{array}$ & Changeable & Multi-faceted space & One side \\
\hline Reloading space & Small & $3+1$ facet & Private & Changeable & Multi-faceted space & One side \\
\hline Multi-faceted space & Small & $1+\mathrm{n}$ facet & Shared & Changeable & Other spaces & $\begin{array}{c}\text { At the centre } \\
\text { of house }\end{array}$ \\
\hline
\end{tabular}

Therefore, based on the classification following the use function and determination of the proper locations of four spaces (fixed space, self-business space, reloading space, and multi-faceted space), this study has proposed an architectural space design proposal for $\mathrm{SH}$ serving self-employed people in HCMC. Especially, solutions for flexible and convenient changes of spaces to help optimize the size and volume of space inside the apartment, serving self-employed people, are emphasized (see Figure 17). 


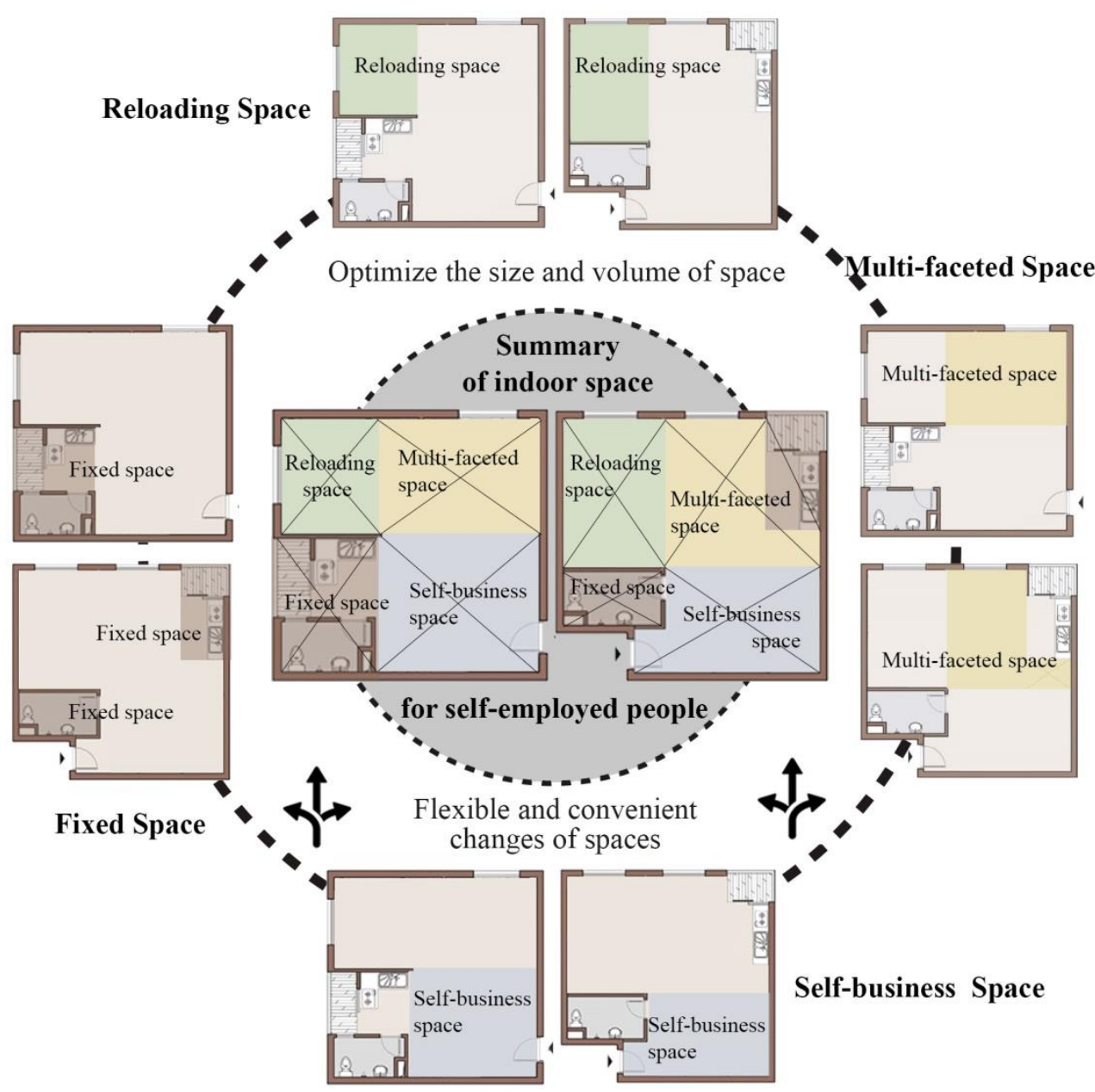

Figure 17. General diagram of four types of spaces in housing for self-employed people.

\section{Discussion}

\subsection{Discuss the Solutions and Results of the Paper}

The research highlights the lifestyle and psychological characteristics of self-employed people and their specific needs in social housing development. The self-employment activities presented in Sections 1 and 3 show the need to organize various types of flexible spaces in $\mathrm{SH}$. The organization of these spaces should be based on the work characteristics of the self-employed people with required workspaces while still ensuring basic family activities. The authors have proposed solutions in organizing social housing spaces for self-employed people in HCMC in terms of construction site selection and design. The solutions have to set the essential housing criteria with quality, accessibility, and archdesign as a priority.

Our research has suggested four types of social housing apartments for self-employed people. These types are composed of a fixed space, reloading space, multi-faceted space, and self-business space. The combination and transition between the four types of space are based on the principle of prestressed space. The priorities in space arrangement consider ensuring the maintenance of living spaces and business space with minimal influences between spaces.

\subsection{Results and Effectiveness of the Solution}

For the land selection for SH construction, the research takes advantage of the available empty spaces in the urban areas. This solution can optimize the urban land by reusing some spaces or redevelopment for trading areas. In addition, this location promotes many people to access the urban public transport and job market. The social housing projects for 
low-income people consider urban's "pending planning" plots. This recommendation can create a new direction in solving the needs of social housing for self-employed people as well as the massive demand on the housing market in HCMC

\subsection{Future Research Directions}

For future research, to ensure the feasibility of social housing projects for self-employed people in HCMC, it is necessary to review legal documents. The regulations need to be reviewed, focusing on social housing projects in vacant public spaces, public-private partnerships in investment, and the mechanism for investment in the social housing project. The details on technical solutions, including movable modular housing architecture with specific building technology, have to be considered with housing management solutions.

\section{Conclusions}

\subsection{Research's Contribution}

This study illustrates the basic issues in developing social housing and sets the foundation for social housing development for workers in Ho Chi Minh City. At the same time, the research provides some insight in solving the housing demand of HCM with the alternative housing forms.

The study clarifies some ambiguous points in understanding "social housing" and "freelance workers or self-employed people" in Vietnam. Finally, the solution comes up with designs for flexible, adaptive living spaces for the specific urban social group.

In addition, our study demonstrates models which may provide ideas to be implemented in various locations of HCMC. The solution recommends a way to effectively use urban land and improve the living quality of housing in $\mathrm{HCMC}$, and many other cities, by reusing and renovating some abandoned or unused urban space. Furthermore, the solution can reduce the pressure on finding investors in social housing development projects.

\subsection{Research's Limitation to Expand the Direction of Further Researches}

The proposed solution concentrates on developing a new small model as a basic apartment for an urban group. For further steps, the research would be conducted in many groups of the community to ensure balancing the benefits of various labor groups in accessing the housing market. Moreover, the right to own or rent social houses would be modified based on the characteristic of migration in HCMC. The site selection for social housing is conducted in part in some districts. Hence, the network of social housing and their relationship with the city centers need to be investigated.

Author Contributions: Conceptualization, L.-M.N. and H.-B.N.; formal analysis, H.-B.N. and T.-P.U.N.; methodology, L.-M.N. and T.-M.D.N.; project administration, L.-M.N.; resources, T.-P.U.N.; software, H.-B.N.; writing-original draft, L.-M.N. and T.-P.U.N.; writing-review and editing, L.-M.N., T.-M.D.N. and H.-B.N. All authors have read and agreed to the published version of the manuscript.

Funding: This research received no external funding.

Institutional Review Board Statement: Not applicable.

Informed Consent Statement: Not applicable.

Data Availability Statement: Not applicable.

Acknowledgments: A portion of the research for this paper was conducted by Le-Minh Ngo, which was made possible by a 2018-2020 Ho Chi Minh City Department of Science and Technology Grant. Le-Minh Ngo also wishes to thank Ton Duc Thang University for hosting the research activities, and to the students and lecturers who participated in the research. Among the contributions, space design solutions were designed and illustrated by the master's students of architecture, under the supervision of Le-Minh Ngo, in 2018-2019.

Conflicts of Interest: The authors declare no conflict of interest. 


\section{References}

1. National Assembly of the Socialist Republic of Vietnam. Law on Housing 2014; National Assembly of the Socialist Republic of Vietnam: Ha Noi, Vietnam, 2014.

2. Ahmed, I.; Jalel, S.; Le Vu, C. Sustainable Urban Low-Income Housing in Vietnam: Context and Policy; Open House International, No. 3; Emerald Publishing Limited: Bingley, UK, 2010; Volume 35. [CrossRef]

3. Le-Minh, N.; Phuong Uyen, N. Social housing for self-employment-A gap that needs development in Ho Chi Minh City. J. Archit.-Vietnam. Assoc. Archit. 2019, 12, 59-63.

4. Asian Development Bank (ADB). Ho Chi Minh City Is Adapting to Climate Change. Report of the ADB Governor Council. 2010. Available online: https:/ / www.adb.org/sites/default/files/.../29380/ho-chi-minh-city-adaptation-vn.pdf (accessed on 28 November 2020).

5. Reeves, P. An Introduction to Social Housing, 2nd ed.; Elsevier Butterworth-Heinemann: Oxford, UK; Burlington, MA, USA, 2005.

6. Labor Magazine, Neighborhood of Lonely Freelance Workers at the Beginning of the Year. Available online: https://laodong.vn/ cong-doan/xom-tro-cua-nhung-lao-dong-tu-do-diu-hiu-dip-dau-nam882253.ldo (accessed on 21 February 2020).

7. Life in Micro-Houses in the Heart of Saigon_HaTinh Paper. Available online: https://baohatinh.vn/van-hoa-giai-tri/cuoc-songtrong-nhung-can-nha-sieu-nho-o-trung-tam-sai-gon/155816.htm (accessed on 4 June 2020).

8. Vietnamese Finalcial Magazine-Why Are Businesses Not Interested in Investing in Social Housing? Available online: https: //tapchitaichinh.vn/thi-truong-tai-chinh/vi-sao-doanh-nghiep-chua-man-ma-dau-tu-nha-o-xa-hoi-323542.html (accessed on 1 October 2020).

9. Le-Minh, N. Research on the Organization of Social Housing Space in Ho Chi Minh City with the Participation of the Community; Science \& Technology Project; Department of Science and Technology of Ho Chi Minh City: Ho Chi Minh City, Vietnam, 2018.

10. Christiane, D.; Thomas, K. Social Housing in Germany. In Social Housing in Europe, 1st ed.; Scanlon, K., Whitehead, C., Arrigoitia, M.F., Eds.; John Wiley \& Sons, Ltd.: Hoboken, NJ, USA, 2014.

11. Usavagovitwong, N.; Pruksuriya, A.; Supaporn, W.; Rak-U, C.; Archer, D.; McGranahan, G. Housing Density and Housing Preference in Bangkok's Low-Income Settlements; Urbanization and Emerging Population Issues Working Paper 12; Human Settlements Group International Institute for Environment and Development (IIED): London, UK, 2013.

12. Astuti, W.; Prasetyo, D.A. Model of Community-based Housing Development (CBHD) of Bedah Kampung Program in Surakarta Indonesia. In Proceedings of the 4th International Conference on Sustainable Future for Human Security, Kyoto, Japan, 19-21 October 2013.

13. Bukovszki, V.; Dóci, G.; Reith, A. Coding Engines in Participatory Social Housing Design—A Case to Revisit Pattern Languages. Sustainability 2021, 13, 3367. [CrossRef]

14. Choguill, C.L. The search for policies to support sustainable housing. Habitat Int. 2007, 31, 143-149. [CrossRef]

15. Tubelo, R.; Rodrigues, L.; Gillott, M.; Zune, M. Comfort within Budget: Assessing the Cost-Effectiveness of Envelope Improvements in Single-Family Affordable Housing. Sustainability 2021, 13, 3054. [CrossRef]

16. Chohan, A.H.; Che-Ani, A.I.; Shar, B.K.; Awad, J.; Jawaid, A.; Tawil, N.M. Model of Housing Quality Determinants (HQD) for Affordable Housing. J. Constr. Dev. Ctries. 2015, 20, 117-136.

17. Michael, W.; Ronald, E.; Michael, B.; Volker, M. Housing for Low-Income Groups in Ho Chi Minh City between Re-Integration and Fragmentation Approaches to Adequate Urban Typologies and Spatial Strategies. Asien 2007, 103, 59.

18. David, A.; Herve, H.; Philippe, P. Urban Development in Vietnam: The Effort of Local Authorities; Department of Traffic and Urban Development, Agence Française du Développement: Focales, France, 2010.

19. BachHoa24.com. Pho restaurant in HCMC. Available online: http://bachhoa24.com/sang-quan-pho-quan-go-vap-cl-1429984. html (accessed on 21 July 2021).

20. Chi, Y.L.; Mak, H.W.L. From Comparative and Statistical Assessments of Liveability and Health Conditions of Districts in Hong Kong Towards Future City Development. Sustainability 2021, 13, 8781. [CrossRef]

21. Triana, M.; Roberto Lamberts, R.; Sassiba, P. Characterisation of representative building typologies for social housing projects in Brazil and its energy performance. Energy Build. 2015, 87, 524-541. [CrossRef]

22. DeKay, M.; Brown, G.Z. Sun, Wind \& Light: Architectural Design Strategies, 3rd ed.; John Wiley \& Sons: Hoboken, NJ, USA, 2014.

23. World Health Organization. Housing and Health Guidelines; WHO: Geneva, Switzerland, 2018.

24. World Economic Forum. Making Affordable Housing a Reality in Cities Report. Available online: http://www3.weforum.org (accessed on 26 July 2021). 